\title{
Analysis of News Item Texts of Kazakhstani Mass Media
}

\author{
Aybarsha Islam \\ Abylai khan Kazakh university of international relations and world languages, Almaty, \\ Muratbayev str.200, 050022, Republic of Kazakhstan
}

\section{Anargul Mukhamedkalymovna Tyutebayeva}

Kh. Dosmukhamedov Atyrau State University, Studencheskiy str. 212, 060011, Republic of Kazakhstan

\section{Doi:10.5901/mjss.2015.v6n4s2p158}

\section{Abstract}

This article focuses on the contemporary issues of mass media in Kazakhstan at present. 8248 media (active 2513 media), 212 electronic media, 2392 media of foreign countries are registered in Kazakhstan, and over 9,000 domain names in the domain $\mathrm{KZ}$ are registered. $85 \%$ make non-governmental media. Currently television channel KazakhTV broadcasts in three languages: Kazakh, Russian and English languages 24 hours. It provides relevant and objective information about Kazakhstan and the events occurring in the world. The channel broadcasts the main local and international news as well as information about major political, economic and sports events. Analyzing translation of KazakhTV news texts it is possible to use different methods of comparative analysis for the theoretical study of news texts identifying linguistically this phenomenon.

Keywords: mass media, news item texts, media texts, translation studies, mass media, text structure, culture marked words, semantic center, news fragment, grammar transformations, TV news texts.

\section{Introduction}

Mass media, or media, is a relatively new social institution, whose function is to produce and disseminate knowledge (Chernyh, 2007).

Media is considered to be a conglomerate structure of private businesses, and is a special kind of social activity; the main task of media is to carry out some kind of representation of various points of view, opinions and attitudes, media is the product of the relevant legal regulations, including regulations with respect to their economic activities. It is a social institution that performs important social problems as well as a means of advertising (Briggs \& Cobley, 2002).

John Carron confirm that: "The influence of the media has been immense: on institutions, the conduct of affairs, and the way in which people think and act politically. The mass media and mass politics have inspired, reflected, and shaped each other more than has commonly been realized...." (Curran \& Seaton, 1991).

Mass communication is the practice and product of providing information and leisure entertainment to an unknown audience by means of corporately financed, industrially produced, state-regulated, high technology, privately consumed commodities in the modern print, screen, audio and broadcast media (O'Sullivan et al., 1994).

Mass communication refers to the process by which a complex organization with the aid of one or more machines produces and transmits public messages that are directed at large, heterogeneous and scattered audiences (Dominick, 1993).

Mass media is a generic term of all forms of communication aimed at a mass audience. These traditionally include newspapers, magazines, movies, radio, television, popular literature and music, and in the last couple of decades it has been completed with the new electronic media, including the Internet (Fourie, 2008).

Since gaining its independence and sovereignty, the Republic of Kazakhstan has started to make radical reforms in the media, and paid special attention to the legislative support of the rights and freedoms of citizens. First of all, this is due to understanding the fact that the availability of advanced, organizationally strong and free media is one of the key indicators of a democratic society. Thus, under the Kazakhstani law, any interference to media world is prohibited and Constitution prohibits censorship. Describing the development of the information market of Kazakhstan since the moment of its independence, several conventional development stages have been identified.

The first stage - the post-Soviet period, the advantage of the state monopoly on mass media (until 1992), there was practically no independent mass media that period. 
The second stage - the stage of formation and growth (1992 - 1996 years), state dominance in the information space and the rapid development of non-governmental media (private, corporate, etc.), reducing the overall share of state-run media.

The third stage - liberal, which is characterized by qualitative and quantitative changes in the market of mass media, mass privatization of former state-owned media, printing companies, the transition from public funding and subsidies for the media from the government order to conduct public information policy. This development stage of domestic information space began in 1996 - 1997.

Today we can affirm that the information market in Kazakhstan has entered the stage of stable growth.

Existing number of quite strong and powerful media, information media holdings is one of the undoubted achievements of the socio-economic and democratic reforms of the country.

In Kazakhstan, the country's constitution guarantees freedom of speech and creativity, it bans censorship, but it enshrines everyone's right to obtain and disseminate information. However, there are restrictions adopted in international practice. According to Paragraph 3 of Article 20 of the Constitution of the Republic of Kazakhstan, propaganda or agitation of violent change of constitutional order, violation of the Republic integrity, disruption of state security, war, social, racial, ethnic, religious, class and clannish superiority as well as the cult of cruelty and violence is not allowed. The aforementioned freedoms, rights and restrictions are given in the Law on "Mass media", Article 2 ("Law of the Republic of Kazakhstan", 1999).

\section{Method}

Media texts studied today in terms of a variety of disciplines - linguistics, sociology, psychology, style, culture, politics, intercultural communication. Integration of different methods for analyzing media texts within Medialinguistics provides a complex representation of the real properties of speech, it's style, especially the effect on the individual and the mass consciousness, the methods of verbal interaction and media levels of ideological modality, the role of culturally significant components.

Analyzing translation of media texts it is possible to use different methods of comparative analysis for the theoretical study of media texts to identify this phenomenon in linguistic terms. There are numerous methods of studying media texts: the method of linguistic analysis, the method of content analysis, or analysis of the content, method of critical linguistics (or rhetorical criticism), the method of linguistic and cultural analysis based on identifying culturally significant components of the text. Every time the translator creates his work performing the act of speech, but also makes the identification of speech to create segments of original text. The translator analyzes two languages, comparing equivalents. It is difficult to imagine the successful development of modern translation studies without a comprehensive study of this experiment and its results, without revealing the mechanism of linguistic cross-language communication and translation accounting facts of our investigation.

There are numerous methods of studying media texts (Nazarov, 2003):

- Methods of linguistic analysis that reveal the basic properties and characteristics of texts in different levels: lexical, semantic, syntagmatic, stylistic and others.

- The method of content analysis, or analysis of the content, based on a statistical calculation of specially selected text units.

- The method of critical linguistics (or rhetorical criticism), allowing to identify the hidden political and ideological component of media texts.

- The method of linguistic and cultural analysis based on identifying culturally significant components of text.

The task of comprehensive comparative analysis of political news blocks, composed in different languages, with emphasis on the structural and substantial aspect of this comparison. The purpose of this analysis is to identify commonalities and differences between two language versions of news fragment in terms of volume, structure and nature of the recipient of the transmitted content. In our researchment we use comparative analysis of English and Russian versions of news fragment of KazakhTV.

\section{Results and Discussion}

Mass media is one of the main instruments for implementing the rights and freedoms of citizens to information. Over the recent years Kazakhstani mass media has undergone dramatic changes. There has been denationalization of the media sector, which resulted in the fact that today more than $80 \%$ of the media are private. Liberalization and market reforms have led to the quantitative and qualitative growth of mass media. Today Kazakhstan is ahead of most countries in 
Central Asia and Transcaucasia in terms of mass media. Leadership for the development of media infrastructure in Kazakhstan is proved by the fact that the annual Eurasian Media Forum is held in Kazakhstan.

8248 media (active 2513 media), 212 electronic media, 2392 media of foreign countries are registered in Kazakhstan, as well as over 9,000 domain names in the domain KZ. 85\% make the non-governmental media (Abramov, 2010).

Newspapers and magazines, television and radio programs are media texts, which published and broadcasted in 11 languages of nations and nationalities living in the country. In addition to the major Kazakh and Russian languages, the media is published and broadcasted in Ukrainian, Polish, German, Korean, Uyghur, Turkish, Dungan, and other languages. Media of ethnic minorities receive financial support from the government.

Internet and cable TV is dynamically developing in Kazakhstan. Modern information technologies are widely used in the information market. National TV and radio stations broadcast via the national satellite system. Satellite channel CaspioNet (operator Eutelsat ) was created in 2002. Cable and satellite channels broadcast programs BBC, CNN, Deutsche Welle, Radio "Liberty", a Polish channel Polonia, Russian and other television and radio channels on the whole territory of the Republic of Kazakhstan.

The Ministry of Foreign Affairs of the Republic of Kazakhstan accredited more than 150 representatives of foreign media from 20 countries, including most major news agencies like BBC, Associated Press, Interfax, France Press, Reuters, ITAR-TASS. Variety of topics, publications and languages contributes to the rapid development of mass media ("Message from the President", 2013)..

Associations for the protection of journalists' rights, Congress of Journalists of Kazakhstan, Union of Journalists of Kazakhstan, Association of Broadcasters of Kazakhstan, representatives of international organizations: the OSCE, the International Bureau for Human Rights, Internews network, «Adil Soz", and others are successfully operating the country.

60 national publications, news agency "Kazinform", channels "Kazakhstan", "Khabar", "Channel 31", "TV Age ", "Rakhat TV" are involved in coverage of human rights in Kazakhstan. These printed media and channels fulfill the state order for state information policy. The following topics have been covered in formulating the state order:

- Legal advocacy;

- Coverage of the legal advocacy;

- Coverage of progress and positive outcomes of the Strategy "Kazakhstan - 2030".

The total volume of these thematic areas made 1110 hours on the channel "Khabar" and "Kazakhstan", 720 hours on the Kazakh Radio, 830 hours on the line "Caspionet".

Objective and focused coverage of the situation of human rights is highlighted in national newspapers and nonpublic media like "Egemen Kazakhstan", "Kazakhstanskaya Pravda", "Aykyn", "Liter", "Express K", "Zan gazeti", "Legal Gazette", "Moscow Komsomolets in Kazakhstan" and others under special headings like "Government ", "Legal reform", "People and the law", "Parliament", "Urgent", "Situation", "Live", "Law and Order", "Human rights", "Need to know", "Attention" and etc.

This subject is also widely highlighted in information and analytical, interactive programs of the leading republican TV channels which are carrying out the state order. In this regard, it we would like to emphasize programs "Zheti kun", "Betpe bet" on TV channels "Khabar" and "Aina-Apta", program "Nazar" on national channel "Kazakhstan", "Private opinion", "Spotlight" on "Channel 31", "Week Panorama" on "Rakhat TV", "Big Ratings" on the channel "Astana TV".

In addition, at present time, for the purpose of developing optimal model of mass media activity on the basis of freedom of speech and independence principles, the government is carrying out purposeful work on interaction with public organizations, associations, international organizations, institutes of mass research on developing mass media.

Kazakhstan applies legally approved methods to support mass media, which are aimed at creating favorable economic conditions so that the media is able to fulfill its public mission, and provide freedom of speech and mass information.

Among the first laws of sovereign Kazakhstan was the Law "On Press and Other Mass Media" in 1991, innovation and democratic norms that have served as a powerful factor in the rapid development of the Kazakhstani press, as well as the Law "On Mass Media" in 1999. Representatives of international organizations, media, and non-governmental organizations participated in designing these laws. The aforementioned laws prohibit censorship and interference in the activities of media organizations from government officials, and are aimed at protecting the rights of journalists ("Law of the Republic of Kazakhstan", 1999).

Kazakhstan holds the opinion that ensuring the rights and freedoms of citizens in obtaining and disseminating information is a prerequisite for building a democratic state. Today we can state that Kazakhstan has formed the major and essential elements of the information market. These include the emergence of a dominant segment of the independent media, a significant differentiation of thematic fields of information, establishment and operation of a sufficiently large media companies. The owners of the 218 publications are voluntary associations, among which 17 
belong to religious organizations. Predominant share of the owners of non-state media (48\%) makes Public limited companies ("Rating of Kazakh mass media", 2000).

In the framework of this concept, it is supposed to pay special attention to the development of information and telecommunications infrastructure (creation of own satellite, modern transceiver stations, etc.). Kazakhstan is starting to introduce digital television, is actively working on the development of national segment of Internet.

Thus, during the years of independence, Kazakhstan has established political, economic and legal conditions for the functioning of independent media.

According to some experts, the information market of Kazakhstan among the Central Asian region is dynamically developing. Mechanisms to ensure the real independence of media, especially from the owner, are being implemented. Kazakhstan is addressing the issue of developing mechanisms to ensure freedom and balance of mass media and their responsibilities to the society. The matter as to strengthen the levers of democratic control of mass media activities is being examined as well.

By the initiative of President of Kazakhstan Nursultan Nazarbayev has introduced a program of "The Trinity of languages in the Republic of Kazakhstan" (Kazakh, Russian and English). The idea of multilingual education was first expressed by the President in October 2006, the Assembly of Peoples of Kazakhstan, in February 2007 in Message "New Kazakhstan in the new world" was proposed the implementation of the cultural project "Trinity of languages in the Republic of Kazakhstan", which was adopted at the state level in July 2007 ("Strategy 2050", 2014).

Currently television channel Caspionet broadcasts in three languages. Caspionet is the first national satellite television channel of the Republic of Kazakhstan. The channel broadcasts in Kazakh, Russian and English languages 24 hours. The purpose of channel is to provide foreign audience with the most complete picture of Kazakhstan.

Kazakh TV is the first national satellite television channel of the Khabar Agency, one of the largest media companies in the Republic of Kazakhstan. The channel's first programme was broadcasted on 25th October 2002 as Caspionet ("Information about KazakhTV", 2015).

Kazakh TV broadcasts informative and educational programmes 24 hours a day in Kazakh, Russian, and English. Via the major satellite operators Eutelsat, Globe Cast and RRsat the channel broadcasts in over 117 countries throughout North and Central America, Western and Eastern Europe, North Africa, the Middle East, Asia, Transcaucasia, Australia and Oceania. It has a potential audience of 5,1 billion people.

It provides relevant and objective information about Kazakhstan and the events occurring in the world. The channel broadcasts the main local and international news as well as information about major political, economic and sports events. The schedules are completed by documentaries, classical and contemporary feature films, children films, programmes of historical and ethnographic interest, and also views of the most interesting events in the cultural life of the country. These may include theatre performances and various exhibitions. Linguistics also have an interest to media texts and it is reflected in "media linguistics" : "Media linguistics brought together a range of papers in the fast developing field of re5earch on media language .. there is now a wide literature in this area, often of highly interdisciplinary nature. Some of this work has focused upon specific genres, such as news discourse, documentary genres and advertising. Increasingly, there is a recognition that language does not stand alone in any type of mass communication, but interacts with other semiotic modes, especially the visual" (Dobrosklonskaya, 2010).

Alan Bell in his book said: "Definitions of media texts have moved far away from the traditional view of text as words printed in ink on pieces of paper to take on a far broader definition to include speech, music and sound effects, image and so on.. Media texts, then, reflect the technology that is available for producing them...." (Bell and Garrett, (eds.), 1998).

"TV news reporting follows a square format, when the information level stays about the same throughout the whole broadcast" (Dominick, 1993).

Analyzing news releases of KazakhTV can be noted that news are broadcasted each hour. At first we analyze television news item texts. TV news texts are media texts, which have several levels: audio and video and the main function is informing about events in chronological order.

The concept of media texts is a limited number of verbal and media units. In contrast to the linear interpretation of the text as a unified common sense sequence of verbal signs, text in mass communication has volume and layering features. It does this by combining the verbal portion of the text with media properties of any media product. Thus, in press the verbal portion of the text combined with graphics and illustration. On the radio a verbal component gets an additional expressiveness with audio facilities - voice quality and music.TV further expands the boundaries of the text, connecting the verbal portion with video and sound together.

It is important to note that the verbal text and media components are closely interlinked and can be combined with each other, basing on various principles: complement, enhance, illustrate, highlight, contrast and so on, forming a kind 
of wholeness, an indivisible unity, which constitutes essence of the concept of "media texts".

The concept of media texts as the volume of multi-level phenomenon is complemented by a constant system of parameters, which allows a very accurate description of media text in terms of the features of its production, distribution channel and linguistic properties. This system includes such important parameters as (Dobrosklonskaya, 2010):

- method of production;

- form of production;

- shape of production;

- distribution channel ( internet, radio, press, TV);

- functional type (news, advertising, features);

- the theme of media texts (topics);

Kazakh TV news texts are broadcasted the same text and the same video in three languages Kazakh, Russian and English. The common quantity of sentences of each topic are about 10-12.

For example Brandon Hennessey writes: "News generally has the qualities of conflict, human interest, importance, prominence, proximity, timeliness and unusualness" (Hennessey, 1989).

Classification of American scientist Dominick J. give us the right to share the newsletter content, which are based on two dichotomous categories «Hard news- soft news», «Local news- foreign news», as well as the allocation of content topics such as politics, business, sports education, culture, etc. (Dominick, 1993).

Kazakh TV news texts have different topics such as Kazakhstan, World, Business, Culture, Sport, Health, Hi-Tech and Cinema. News item texts have a neutral style without any emotive moments.

The purpose of channel is to provide foreign audience with the most complete picture of Kazakhstan. KazakhTV has its own broadcasting policy. The chronometry of Kazakhstan topic is longer than the other topics. It is pragmatically oriented to give the full picture to foreign audience about Kazakhstan.

The analysis of Kazakhstan topic shows that there are a large number of cultural-marked words denoting objects and phenomena that are specific to a given social culture community. It should be noted that translators should orient to international level, they should add an explanation which would be understandable for foreign audience. For example: the Majilis, which translates sounds Kazakh MPs. Kazakh MPs - members of Parliament, in abbreviated form Kazakh MPs. Cultural-marked word oralmans, literally translated from the Kazakh language as "returnee". There no english equivalent. In English version of KazakhTV news fragment it is used the following translation of «refugee of repatriate». EnglishRussian Dictionary «Lingvo Universal» gives us the following definition of "refugee". The law of the Republic of Kazakhstan "On Migration" from December 13, 1997 gives the following definition of "oralman." "Oralmans - foreigners or stateless persons of Kazakh nationality, permanent residence at the time of acquisition of the sovereignty of the Republic of Kazakhstan abroad and arrived in Kazakhstan for permanent residence." In our opinion it is selected an incorrect equivalent, we suggest the following translation solution on base of a descriptive translation: oralman, Kazakh representatives returned to historical Motherland (Tyutebayeva, 2014).

English authors headline word-combination and collocation: " In English as in other . there many fixed, identifiable, non-idiomatic phrases and constructions, or collocation." (Benson, 1986).

Often Kazakh TV news texts have such lexical connections : local authorities, agricultural services, new agreement, new monetary system, appropriate moment, friendly reference, temporary arrangement, common agricultural policy, strong support, agricultural services, new agreement, president of the Republic of Kazakhstan, governor of region and etc.

Also we faced with" news from the place of event" in news release of KazakhTV fragments, for example, American writer Tuchman said that: "The definition of "news from the scene", describe the circumstances, where information gathered" (Tuchman, 1978).

Then you can mark messages that contain a hidden link to the source of information. Hidden because the source is not directly stated, however its existence is implied by the use of certain phrases. We are talking about passive constructions with verbs: to inform, to report, to know, to say the type to be reported, to be said, to be known.

In World topic of KazakhTV news fragment we are faced with international constant words and abbreviations such as UN- United Nations, EU- European Union, OSCE- Organization for Security and Co-operation in Europe, CISCommon wealth of Independent States and UNESCO- United Nations Educational, Scientific and Cultural Organization and etc. 


\section{Conclusion}

Informational TV news texts of KazakhTV are neutral, without no emotive expressions, no live broadcast and translation is adequate.

Expecting all material of informational television news texts, firstly the informational range is framing on parallel on several levels, the level of video, language level and the level of sound. Text, image and sound are equal to the amount of information and the need to combine these series so as to achieve the same effect, which gives us a script. Combine these series translator helps synchronize video. When translating texts on television news has to ensure that the text matches the visuals, and if necessary, apply compression or additions.

The professional competence of the translator is largely determined by how freely he decodes the style of television news and determines stylistic dominant. In other words, the aggregate amount of the researching of speech of mass media needs in comparing, which made it possible to define a new direction - mediatranslation or translation of mediatexts.

Thus, the main feature of TV news texts carried out in a certain levels: a video level, which give the picture of each event and of course, sound registration, with what we can listen the information, and actually characterized at the level of language.

The most important property of television news texts is an objective form of presentation of information (impartiality), reflecting a commitment to neutrality, depersonalization. This fact is explained by the absence of authorship news text, the method of creating a collegial, distributed on behalf of a group of people: the editorial board, television, news agency.

Thus, we can conclude that as the basic unit of language, media text is a complex, multilevel and multidimensional phenomenon.

\section{References}

Chernyh, A., (2007). World of contemporary media. Moscow

Briggs, A. \& Cobley, P. (2002). The media: an introduction. Pearson Education Limited.

Curran, J. \& Seaton J., (1991). Power without Responsibility: the Press and Broadcasting in Britain. London: Routledge.

O'Sullivan T. et al., (eds.), (1994). Key concepts in Communication and Cultural Studies. London: Routledge.

Dominick, J.R., (1993). The Dynamics of Mass Communication. New York: McGraw-Hill.

Fourie, P.J., (2008). Media Studies: Media History, Media and Society. Juta and Company.

Nazarov, M.M., (2003). Mass communication in modern world: Analysis methodology and practice of research. Moscow.

Abramov, V., (the project leader), (2010). Project"Analysis of interaction between the mass media and political parties in Kazakhstan", Almaty.

Message from the President of the Republic of Kazakhstan Nursultan Nazarbayev to the people of Kazakhstan. (December, 14, 2013), Strategy "Kazakhstan 2050" New political direction, http://www.akorda.kz/ru/page/page_poslanie-prezidenta-respublikikazakhstan-n-nazarbaeva-narodu-kazakhstana-14-dekabrya-2012-g_1357813742

Law of the Republic of Kazakhstan dated July 23, 1999 № 451-I On the Media (as amended as of 03.07.2014) (1999, July 23). Retrieved March 11, 2015, from http://online.zakon.kz

Rating of Kazakh mass media. (2000, April 11). Internet gazeta-Zona.kz, from https://zonakz.net/articles/12144

Strategy 2050. (2014, November 29). The President of the Republic of Kazakhstan call people to learn three languages from http://strategy2050.kz/ru/news/3792

Information about KazakhTV. (2015, March 11). About us, from http: //kazakh-tv.kz.

Dobrosklonskaya, T.G. (2010). The study of media texts: The experience of modern English speech (3rd. ed.) Moscow: KRASAND, P.75-77

Bell \& Garrett, (eds.), (1998). Approaches to Media Discourse. Oxford: Blackwell

Dominick, (1993). The Dynamics of Mass Communication. New York: McGraw-Hill, p. 348

Dobrosklonskaya, T.G. (2010). The study of media texts: The experience of modern English speech (3rd. ed.) Moscow: KRASAND, pp: $75-77$

Hennessey, B. (1989). Writing Feature Articles. A practical guide to methods and markets. London: Focal Press.

Tyutebayeva, A.M. (2014). Modeling of translation of TV news texts. (Unpublished master's thesis). Abylai khan Kazakh university of international relations and world languages, Almaty, Kazakhstan.

Benson, M., (1986). The BBI combinatory Dictionary of English. A guide to word-combinations. Amsterdam: John Benjamins.

Tuchman, G.(1978) Making news, New York: Pantheon Books 